\title{
correspondence
}

\section{Computer prehistory}

SiR,--Professor Wilkes (October 16) identifies the prehistory of computers with "the life's work of just one man, Charles Babbage (1792-1871)". If Babbage's work is likened to the prehistory of the subject, how is one to classify the elaboration of the real first arithmetical machine, almost two centuries earlier, by Blaise Pascal?

Pascal invented and built his arithmetical machine in 1643 , at the age of 19, and obtained a patent for it (Privilège pour la Machine d'Arithmétique de $M$. Pascal) in 1654, at which time he had already constructed more than 50 different models. Although Babbage wrote in rather denigrating terms of "the contrivances of Pascal and others" (which actually worked) as compared to his own engines (which did not), Pascal's invention was indeed fundamental, and the actual precursor of all mechanical computers, including Babbage's.

A number of Pascal's machines are still in existence, for example, at the Conservatoire des Arts et Métiers in Paris. A detailed description of the mechanism and principles of Pascal's arithmetical machine was published in 1751.

$$
\text { C. J. VAN OSS }
$$

State University of New York,

Buffalo, New York 14214

\section{EEC directives}

Sir,-As a member of the Conservation Society since its inception, and being much concerned about pollution, I would like to support Eric Ashby (October 16) against Paul French (November 6). The latter may be right in his final statement to the effect that other Europeans are more willing to tackle pollution than are the British. As a result of their efforts, for all I know, the Rhine may now, like the Thames, have more fish in its lower reaches than it has had for 150 years.

But his insistence that identical risks should apply everywhere is absolutely unreasonable. In the denser parts of big cities a complete ban on the burning of smoky fuels has reduced by several times the level of smoke pollution. It would not have been sensible to apply the same rules to villages and isolated farms in the country. Not only would uniform laws for town and country have led to a large extra cost for little useful achievement, but, much more seriously, such laws would never have been passed. I do not believe that in any country in Europe costly and novel proposals, however valuable in the long run, will fail to arouse some opposition. If they can be shown to be technically unreasonable over large areas, opposition will be much greater.

I can see that administrators like to have a uniformly applicable formula, against which performance can be judged. The new formula, which says that pollution is equally important everywhere, is a real advance on the previous non-formula which in effect said that most pollution was of no importance whatever.

It would not seem any more difficult, however, to use a formula which recognised that pollution is more important if more people are polluted. One would do better with a formula based on the square of this number, since if an area has twice as many people they are likely to produce twice as much pollution and there are twice as many to suffer this double pollution. A linear system (the importance of pollution being finite for zero population) would be much easier however, as the standard effluent permitted in any area could then be fixed only in terms of the slowly changing population in the affected area and not at all by the statistically larger fluctuations of the numbers of polluting factories.

Like Mr French, I would be entirely in favour of Britain spending $£ 100$ million a year on reducing pollution (and simultaneously, perhaps, unemployment). But to spend this on reducing pollution in the Atlantic Ocean rather than in the thousands of kilometres of rivers in which no fish can live would be a technical and economic stupidity that has nothing to do with politics or nationalism.

JoHN H. FremLin

\section{University of Birmingham, UK}

Sir,- I am not prepared to accept the whole of Lord Ashby's thesis, contained in his comments on the EEC pollution debate. He states, for instance, that "rabid conservationists need to be reminded sometimes that all pollution, except that from atomic weapons, is a by-product of processes which benefit society." I would have thought that conservationists-rabid or otherwise-are merely saying that any process which endangers the environment for future generations cannot possibly be regarded as beneficial to society.

Again it seems to me complacent, to say the least, to accept a report published by the Medical Research Council 16 years ago as a justification for pouring more sewage on to our beaches and noxious chemicals into our rivers, even though myriads of microbes may be working late into the night to lessen this evil.

Lord Ashby also refers to the phoney arguments. What can possibly be more phoney than his own argument that a cost of $£ 100$ million to reduce pollution is prohibitive when we spend many more millions every year on luxuries such as gambling?

Tenby, UK

\section{W. J. Davies}

\section{Offshore structures}

SIR,-We have had some experience with modelling offshore structures in the laboratory, and wish to call attention to the need for better understanding of the engineering problems likely to arise as drillings are made in deeper and deeper water. Mishaps that have already occurred have been serious enough, but the failure of one of the giant rigs or platforms now being planned would be a catastrophe of unprecedented proportions.

Waves not only exert the major load, which is horizontal and fluctuating, but they also affect the sea bed under and around the structure. The interaction is complicated and difficult to model, but studies and fragmentary prototype data have provided some clues. The foundation and anchorage problems assume greater importance as structures grow in depth.

Although some research seems to be in progress, there is little doubt that it has only just commenced. The present programmes are carried out for private industry whereas research on hydraulic phenomena was formerly for government agencies. Past results were thus public, but the present research is mainly ad hoc and confidential, in the long term being more costly to all concerned. Reasons for mishaps now tend to be kept secret for political or commercial reasons.

Basic issues should be investigated openly by university and similar institutions, if only so that controlling authorities and insurance agencies can establish design criteria.

University of Connecticut

Chesley J. Posey

Richard Silvester

University of Western Australia 